\title{
A Program's Analysis of Communication Methods With Clinical Preceptors
}

\author{
Nicholas M. Hudak, MPA, MSEd, PA-C; April Stouder, MHS, PA-C; \\ Christine M. Everett, PhD, MPH, PA-C
}

\begin{abstract}
Purpose Preceptors value communication with physician assistant (PA) educational programs. This study describes preceptors' perspectives about one PA program's established and new communication strategies to promote preceptor development and retention.
\end{abstract}

Methods An electronic survey of preceptors was conducted in December 2014. Quantitative and qualitative data were analyzed using descriptive statistics.

Results Eighty-eight of 209 preceptors completed the survey (42\% response rate). Preceptors reported satisfaction with communication frequency and quality. The most preferred topics were preceptor benefits, teaching strat- egies, feedback about students' performance, and program policy updates. Many preceptors reported not receiving communications sent by mail. A majority of preceptors preferred site visits at least once per year and in person.

Conclusions Understanding preceptors' preferred topics helped the study program increase its emphasis on those topics. Knowledge that many preceptors do not receive mailed communications has prompted the program to use electronic communication for all communication types. The results reinforced the program's approach to site visits.

\section{Feature Editor's Note:}

The number of physician assistant (PA) training programs continues to grow at an exponential rate, as the national press promotes the profession as financially lucrative, fulfilling, and central to modern health care delivery. As the number of programs grows, the number of required preceptors increases, straining existing resources. Recruiting preceptors, retaining skilled preceptors, and providing professional development and other intrinsic and extrinsic incentives pose significant challenges. Hudak et al explored preceptor beliefs as a function of the quality and nature of communications between a PA program and its preceptors. Frequency and quality of contact, whether through electronic means or inperson site visits, were paramount. Although this work does not address recruitment and retention directly, understanding the impact of different communication methods bolsters ongoing research efforts to better understand and support these critical training relationships.

\section{Doug Brock, PhD}

\section{INTRODUCTION}

Maintaining clinical training sites remains one of the most pressing challenges in health professions education. ${ }^{1}$ Physician assistant (PA) programs establish and maintain educa-

\footnotetext{
The authors declare no conflict of interest.

J Physician Assist Educ 2018;29(1):39-42

Copyright (@ 2018 Physician Assistant Education Association

DOI 10.1097/JPA.0000000000000184
}

tional partnerships with clinical preceptors who provide students with supervised clinical experiences. Programs and preceptors communicate for a variety of reasons, including explaining responsibilities, evaluating student performance, reporting student issues, scheduling rotations, and providing resources for preceptor development. ${ }^{2}$ Given the increased competition for clinical sites among health professions education programs, PA faculty members must use effective communication methods to maintain strong relationships with preceptors.

Evidence suggests that effective communication with programs is valued by preceptors and influences their decision to precept. A recent national survey of PAs identified support from PA programs as a factor influencing PAs' involvement as clinical preceptors. ${ }^{3}$ A follow-up qualitative study reported that preceptors value feeling connected with PA programs through initial and ongoing communication. ${ }^{4}$ Another PA education study concluded that preceptors and students value site visits for improving communication and quality of education experience. ${ }^{5}$ Among other health professions, preceptors of nurse practitioner students have also identified communication with faculty as the key factor in continued willingness to precept. ${ }^{6,7}$ These studies share the common conclusion that preceptors value effective communication with programs, and 2 of the studies specifically report that the quality of communication affects decisions to precept. ${ }^{6,7}$ However, there are few studies that describe preceptors' perceptions of what communication topics are most important and their preferences regarding communication method.

The study program conducted this research to learn more about preceptors' perceptions of communication after the program implemented new communication strategies to 
Table 1. Communication Strategies

\begin{tabular}{|c|c|c|c|}
\hline & Communication Method & Purpose & Frequency \\
\hline \multicolumn{4}{|l|}{ Established strategies } \\
\hline Rotations and schedule & Electronic & $\begin{array}{l}\text { Course objectives, evaluation, scheduling, and } \\
\text { preceptor responsibilities }\end{array}$ & Ongoing \\
\hline Site visits & In-person & Preceptor and student experience at clinical site & Annual \\
\hline Appreciation letter & Paper by mail & Gratitude for clinical teaching & Annual \\
\hline \multicolumn{4}{|l|}{ New strategies } \\
\hline Introduction letter & Electronic & $\begin{array}{l}\text { Student name, previous health care experience, } \\
\text { and completed rotations }\end{array}$ & Ongoing \\
\hline Preceptor newsletter & Paper by mail & $\begin{array}{l}\text { Program updates, student profiles, preceptors' } \\
\text { pearls, and teaching strategies }\end{array}$ & Twice a year \\
\hline Feedback letter & Paper by mail & $\begin{array}{l}\text { Information about student experiences from } \\
\text { course surveys and student-patient logging }\end{array}$ & Annual \\
\hline
\end{tabular}

promote preceptor development and retention in the context of clinical training site shortages.

\section{METHODS}

In 2012, new strategies to strengthen communication with preceptors were implemented, including (1) annual feedback letters summarizing data from students' evaluations of clinical sites, (2) a preceptor newsletter, and (3) introduction letters to sites with more detailed information about assigned students. These new strategies were incorporated with established communications and then were evaluated as a single intervention after 2 years (Table 1). A survey was designed to describe preceptors' perceptions of the efficacy and utility of communications with our program and to identify opportunities for improvement as part of the ongoing program selfstudy for accreditation purposes.

A single electronic survey of current clinical preceptors was sent in December 2014. The survey included 5 demographic questions, 3 questions about overall satisfaction with program communications, and a series of questions for each communication strategy. Questions for each strategy assessed receipt of communication, satisfaction with communication, utility of communication, and preferred method of communication. The survey also included free text response for comments. Analysis of deidentified, quantitative, and qualitative data was conducted using descriptive statistics. Qualitative analysis involved review of all participant-written comments, including outliers with dissatisfied responses, to better understand responses indicating dissatisfaction. This study was declared exempt from review by our institutional review board.

\section{RESULTS}

Eighty-eight of 209 preceptors completed the survey (42\% response rate). Preceptors included physicians (48\%), PAs (44\%), nurse practitioners (7\%), and a certified nurse-midwife (1\%). The preceptors practiced in a variety of specialties in both inpatient and outpatient settings. On the basis of the profession type, it seems that the respondent sample was representative of all of the program's preceptors. Overall, preceptors reported satisfaction with the frequency (91\%) and quality (96\%) of communication with our program. The most common desired outcomes of communication were to learn about preceptor benefits (51\%), learn teaching strategies (51\%), share feedback about students' performance (47\%), receive updates about the program (46\%), and receive information about program policies (46\%). Most preceptors prefer site visits at least once per year, (64\%) as opposed to once every 2 years (28\%). Most preceptors prefer that site visits be conducted in person (63\%), whereas other preceptors had no preference (26\%). Many preceptors reported that they do not receive certain types of communication, particularly those sent by standard mail, including preceptor newsletters (47\%), feedback letters from student surveys (48\%), and letters of appreciation (25\%). Most preceptors reported a preference for communicating by email about student scheduling (86\%) and submission of evaluations (53\%) and for all other correspondence (64\%). Participants' written comments were infrequent and did not provide additional information or themes. Qualitative analyses of outliers with dissatisfied responses were infrequent and did not increase the understanding of dissatisfaction responses.

\section{DISCUSSION}

Preceptors' perceptions of the new communication strategies were generally positive, but we identified some areas for improvement. Preceptors reported high levels of satisfaction with communication from our program, including frequency and quality. Although this general perception validated the efficacy of our communication approach in broad terms, subsequent questions about communication topics and methods revealed areas for potential improvement. Although respondents expressed satisfaction about the quality and content of the communications, they said that format and communication method were critical to successful communication.

\section{Preceptors Prefer Communication on Specific Topics}

Preceptors reported that their most preferred topics of communication were learning about preceptor benefits, learning teaching strategies, sharing feedback about students' performance, receiving updates about the program, and receiving information about program policies (Figure 1). Gaining 
Learn about preceptor benefits (library privileges, consulting faculty appointments, continuing education credits)

Learn strategies for teaching in clinical environments

Opportunity to share my feedback about student performance

Receive information about program policies related to clinical education

Receive news and updates about the program

Report student evaluations

Schedule students

Opportunity to share feedback about my experience as a preceptor

Report concerns about specific student's performance

$$
\text { Other }
$$

Percentage

$0 \%$

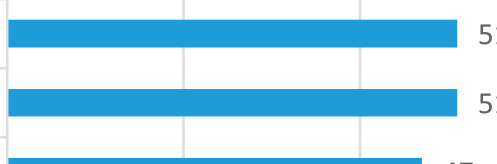

51

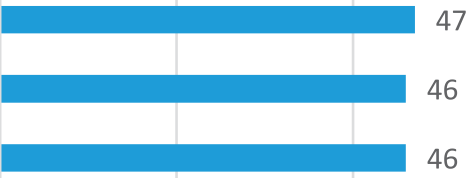

47

46

46
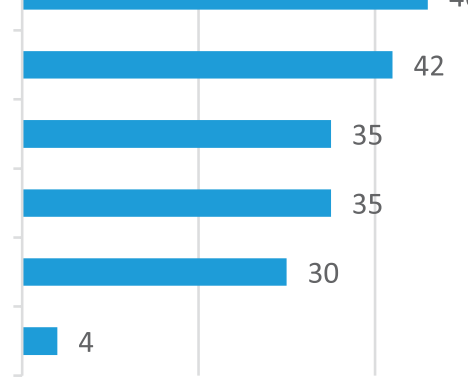

$40 \%$

$80 \%$

$100 \%$

Figure 1. Preceptors' preferred topics of communication

a better understanding of preceptors' preferred topics has helped us increase emphasis on those topics across several communication strategies. For example, during routine site visits, faculty members emphasize preceptor benefits offered by our program, which include Category I continuing medical education credits for PA preceptors, electronic access to the medical center library, and appointments for consulting faculty. Preceptors' interest in these types of incentives is consistent with findings from the PA education literature. ${ }^{3}$ During site visits, faculty members are also more deliberate about discussing teaching strategies that can be implemented in clinical settings. In addition, outside the context of site visits, we are now more deliberate in sending periodic emails and preceptor newsletters to share updates about the program, including policy changes.

\section{Preceptors Prefer to Communicate by Email}

Survey items related to preceptors' receipt of communications indicated that many preceptors were not receiving some of our communications. In addition, analysis of the dissatisfaction response outliers to multiple questions indicated 2 patterns related to the method of communication. The first pattern was respondents reporting dissatisfaction if communications were not received, which underscores the importance of our effort to maximize the number of preceptors receiving communications. The second pattern was respondents reporting dissatisfaction with nonelectronic forms of communication, which supports our effort to communicate electronically. Learning that preceptors are not receiving certain types of communication has prompted our program to optimize methods of communication. Our program has subsequently adopted email as the primary form of communication with preceptors. Because some preceptors report a preference for nonelectronic forms of communication, preceptors may request nonelectronic communication. The authors recognize that email communication may not ensure receipt by preceptors, and in the future, they intend to reevaluate the effectiveness of using email as the primary form of communication.

\section{Preceptors Value Routine In-Person Site Visits}

Preceptors reported valuing site visits for communication related to specific topics. This finding is consistent with a recent study, in which preceptors strongly felt that site visits improved communication with programs, allowed for clarification of program expectations and discussion about site issues, and improved the student's experience. ${ }^{5}$ Most preceptors reported a preference that site visits be conducted in person and at least once a year, which reinforced our program's standard practice. Many preceptors reported a preference for a site visit at least once every 2 years $(28 \%)$ and had no preference for whether visits were conducted in person or remotely (26\%). These findings add to the existing literature that preceptors have different needs and expectations for site visits. 5,6,8 These factors can be considered when determining the program policy about site visits and while communicating with individual preceptors about the plan for site visits. Despite these findings, our program has maintained the goal of conducting site visits annually and in person.

\section{Strengths and Limitations}

To the authors' knowledge, this study is the first of its kind to describe preceptors' perceptions of communication with a single PA program. Although the response rate was relatively low, the respondent sample was found to be fairly representative of all clinical sites by specialty and profession type. The survey response was limited to the preceptor of record at each site to prevent multiple responses from a single site. Although the authors do not believe that the responses are representative of all preceptors, the survey method and themes identified may be relevant and applicable to other programs and their preceptors. This study was not designed to assess the effect of communication on continued precepting, although this effect has been reported in other studies. ${ }^{3,6,7}$

\section{CONCLUSION}

Maintaining and optimizing communication with our preceptors remains a top priority for our PA program and is 
a major way by which we support these essential clinicianeducators. In addition, given the shortage of clinical sites and increasing competition among health professions programs for those sites, we believe that effective communication helps our program retain preceptors and assist with preceptor recruitment. The outcomes of this study have informed our program's communication efforts and may provide PA educators with examples of communication strategies and methods to implement in their own programs. The survey content described may also be of value to programs interested in both understanding their preceptors' perceptions of communication and improving communication with preceptors on the basis of those perceptions.

Further research is needed to assess the effect of program communication, among other factors, on the recruitment, retention, and development of clinical preceptors. Other research could aim to study the resources required, including time and effort for both faculty and staff, to maintain effective communication with preceptors.

Nicholas M. Hudak, MPA, MSEd, PA-C, is an associate professor in the Department of Community and Family Medicine, Duke University School of Medicine, and clinical coordinator for the Duke University Physician Assistant Program in Durham, North Carolina.

April Stouder, MHS, PA-C, is the director of clinical education at the Duke University Physician Assistant Program in Durham, North Carolina.

Christine M. Everett, PhD, MPH, PA-C, is an assistant professor of Community and Family Medicine for the Duke University Physician Assistant Program in Durham, North Carolina.
Correspondence should be addressed to: Nicholas M. Hudak, MPA, MSEd, PA-C, Department of Community and Family Medicine, Duke University School of Medicine, DUMC Box 104780, Durham, NC 27710. Telephone: (919) 681-3254; Email: Nick.Hudak@duke.edu

\section{REFERENCES}

1. American Association of Colleges of Nursing, American Association of Colleges of Osteopathic Medicine, Physician Assistant Education Association, Association of American Medical Colleges. Recruiting and Maintaining U.S. Clinical Training Sites: Joint Report of the 2013 Multi-Discipline Clerkship/Clinical Training Site Survey. https:// members.aamc.org/eweb/upload/13-225\%20wc\%20report\%202\% 20update.pdf. Accessed November 29, 2017

2. Physician Assistant Education Association (PAEA). Clinical Educator Handbook. Washington, DC: PAEA; 2015. http://paeaonline.org/ publications/clinical-educator-handbook/. Accessed November 29, 2017.

3. Gonzalez-Colaso R, Moloney-Johns A, Sivahop J. To teach or not to teach: 2011 national survey of physician assistants and preceptor experiences. J Physician Assist Educ. 2013;24(2):12-19.

4. Hudak NM, Enking PJ, Gorney C, Gonzalez-Colaso R. Tales from the trenches: physician assistants' perspectives about precepting students. J Physician Assist Educ. 2014;25(1):12-19.

5. D'Aquila M, Lie D. Preceptors' and physician assistant students' views about the value of site visits. J Physician Assist Educ. 2015:26(1):40-42

6. Brooks MV, Niederhauser VP. Preceptor expectations and issues with nurse practitioner clinical rotations. J Am Acad Nurse Pract. 2010;22 (11):573-579

7. Lyon DE, Peach J. Primary care providers' views of precepting nurse practitioner students. J Am Acad Nurse Pract. 2001;13(5):237-240.

8. Burgett NE, Dennis VC, Wideman SD, Kirkpatrick AE, Randall DL. Pharmacy preceptors' views on the value and optimal frequency of quality assurance visits to advanced pharmacy practice experience sites. Am J Pharm Educ. 2012;76(3):48. 